\title{
Phylogenetic Interrelationships of Round-Spore-Forming Bacilli Containing Cell Walls Based on Lysine and the Non- Spore-Forming Genera Caryophanon, Exiguobacterium, Kurthia, and Planococcus
}

\author{
JOHN A. E. FARROW, SALLY WALLBANKS, AND MATTHEW D. COLLINS* \\ AFRC Institute of Food Research, Reading Laboratory, Reading RG6 2EF, United Kingdom
}

\begin{abstract}
The 16S rRNA gene sequences of "Bacillus aminovorans" and several species considered to be phylogenetically related to the group 2 bacilli of Ash et al. (C. Ash, J. A. E. Farrow, S. Wallbanks, and M. D. Collins, Lett. Appl. Microbiol. 13:202-206, 1991) were determined. A comparative analysis of the sequence data revealed that the round-spore-forming group 2 bacilli, together with some asporogenous taxa (the genera Caryophanon, Exiguobacterium, Kurthia, Planococcus), form a phylogenetically distinct cluster that is only remotely related to Bacillus subtilis, the type species of the genus Bacillus. Within this cluster, planococci, kurthiae, Caryophanon spp., and two lines defined by Bacillus sphaericus and Bacillus fusiformis and by Sporosarcina ureae, Bacillus pasteurii, Bacillus globisporus, and Bacillus psychrophilus were found to be distinct genera. Exiguobacterium aurantiacum and Brevibacterium acetylicum were found to form a distinct clade, which was peripherally related to this cluster. " $B$. aminovorans" exhibited no specific relationship with the group 2 bacilli or with any of the other reference species examined.
\end{abstract}

It has been recognized for a long time that the genus Bacillus is phenotypically extremely diverse (5). Smallsubunit 16S rRNA cataloging $(6,17,33,34)$ and, more recently, sequencing studies $(2,12,29)$ have also revealed very considerable phylogenetic heterogeneity within the genus. On the basis of the results of comparative analyses of almost complete 16S rRNA sequences, the genus Bacillus has been shown to comprise a minimum of six phylogenetic groups (2). The thermophilic species Bacillus cycloheptanicus, Bacillus acidocaldarius, and Bacillus acidoterrestris have recently been transferred to a new genus, Alicyclobacillus (36), and the remainder of the genus Bacillus is clearly in need of taxonomic revision.

All of the Bacillus species included in the second phylogenetic group of Ash et al. (2), designated the group 2 bacilli, have round spores and a murein based on L-lysine or D-ornithine (33). Members of this group have been shown to be phylogenetically distinct from Bacillus subtilis, the type species of the genus, and from all other meso-diaminopimelic acid-containing bacilli examined to date. $16 \mathrm{~S}$ rRNA oligonucleotide cataloging studies $(17,33,34)$ have revealed that the genus Sporosarcina $(17,33)$ and several asporogenous taxa (including the genera Planococcus [33] and Caryophanon [33]) are phylogenetically related to these round-spore-forming bacilli. Within the overall group, cataloging also revealed additional specific relationships between members of these genera and particular Bacillus species (for example, between Sporosarcina ureae and Bacillus pasteurii and between Planococcus citreus and "Bacillus aminovorans") (33). The relationship between $S$. ureae and Bacillus pasteurii $(17,33)$ has been confirmed by the results of sequencing studies $(2,12)$.

Numerous other taxa exhibit some of the phenotypic traits of the group 2 bacilli. Species of the genus Kurthia contain cell walls based on L-lysine $(3,32)$ and possess similar respiratory quinones (8). Cataloging studies (33), however,

\footnotetext{
* Corresponding author.
}

have failed to reveal any close phylogenetic affinity with the group 2 bacilli and their relatives. The alkalophilic bacterium Exiguobacterium aurantiacum (10) also has several chemotaxonomic features in common with the group 2 bacilli, but this organism was considered to be sufficiently distinct to warrant a separate genus. It has been suggested $(9,20)$ that Brevibacterium acetylicum may be related to the genus Exiguobacterium rather than to Brevibacterium linens. The phylogenetic position of the genus Exiguobacterium and Brevibacterium acetylicum within the gram-positive bacteria has not been investigated.

It is now clear that the species that are included in the group 2 bacilli are only distantly related to Bacillus subtilis $(2,12)$. Although the group 2 bacilli and their relatives have been quite extensively studied by using oligonucleotide cataloging $(6,17,33,34)$, it is now recognized that this technique is not as accurate as full sequence analysis for elucidating precise phylogenetic groups and branching orders (37). It is therefore essential that the detailed interrelationships of the group 2 bacilli and possibly related taxa be resolved with confidence before proposals regarding the taxonomic status of members of this group are made.

In this paper we describe the 16S rRNA gene sequences of "Bacillus aminovorans" and six asporogenous species related to the group 2 bacilli. In addition, the results of a comprehensive analysis of the genealogical structure of the group 2 Bacillus cluster are described.

\section{MATERIALS AND METHODS}

Strains, media, and growth conditions. "Bacillus aminovorans" NCIMB $8292^{\mathrm{T}}$ ( $\mathrm{T}=$ type strain), Exiguobacterium aurantiacum NCIMB $11978^{\mathrm{T}}$, Kurthia zopfii NCIMB $9878^{\mathrm{T}}$ and Kurthia gibsonii NCIMB $9758^{\mathrm{T}}$ were grown on nutrient agar no. 2 (25 g/liter; catalog no. CM67; Oxoid). Brevibacterium acetylicum NCIMB $9889^{\mathrm{T}}$ was grown on coryneform agar, which contained (per liter of distilled water) $10 \mathrm{~g}$ of a tryptic digest of casein, $5 \mathrm{~g}$ of yeast extract, $5 \mathrm{~g}$ of D-glucose, $5 \mathrm{~g}$ of $\mathrm{NaCl}$, and $15 \mathrm{~g}$ of agar ( $\mathrm{pH} 7.2)$. Caryophanon latum 


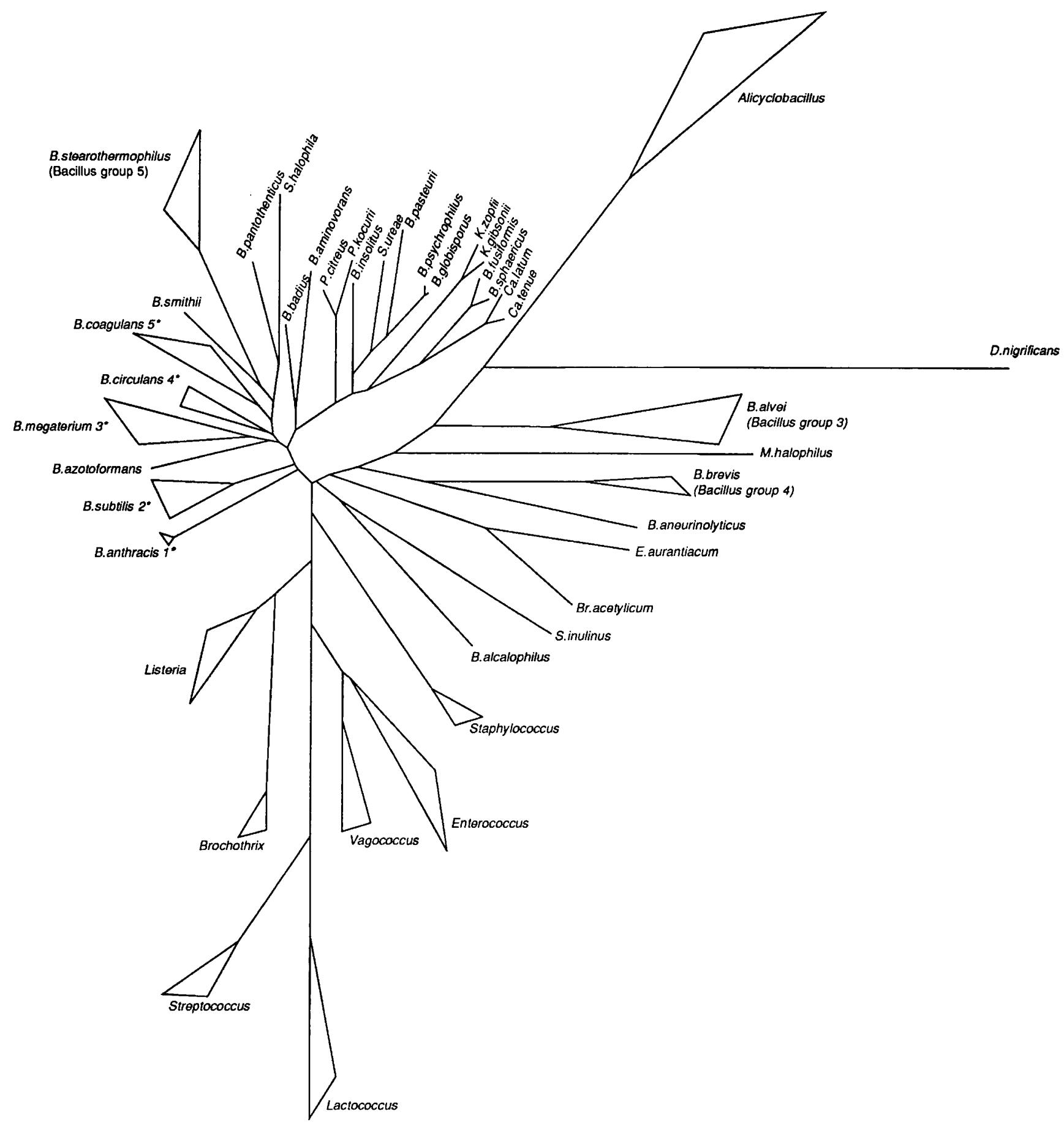

FIG. 1. NJ tree for group 2 bacilli and reference strains. Abbreviations: B. anthracis 1*, Bacillus anthracis, Bacillus cereus, "Bacillus medusa," Bacillus mycoides, and Bacillus thuringiensis; B. subtilis $2^{*}$, Bacillus subtilis, Bacillus amyloliquefaciens, Bacillus atrophaeus, Bacillus lautus, Bacillus lentimorbus, Bacillus licheniformis, Bacillus popilliae, and Bacillus pumilus; $B$. megaterium $3^{*}$, Bacillus fastidiosus, "Bacillus maroccanus," Bacillus megaterium, Bacillus psychrosaccharolyticus, and Bacillus simplex; B. circulans 4*, Bacillus benzoevorans, Bacillus circulans, Bacillus firmus, and Bacillus lentus; B. coagulans $5^{*}$, Bacillus coagulans and Bacillus methanolicus; B., Bacillus; S., Sporosarcina; K., Kurthia; Ca., Caryophanon; D. , Desulfotomaculum; M., Marinococcus; E., Exiguobacterium; Br., Brevibacterium; P., Planococcus.

NCIMB $9533^{\mathrm{T}}$ and Caryophanon tenue NCDO $2324^{\mathrm{T}}$ were grown on caryophanon agar, which contained (per liter of 10 mM Tris-HCl buffer [pH 7.8]) $2 \mathrm{~g}$ of a tryptic digest of casein, $2 \mathrm{~g}$ of yeast extract, $2 \mathrm{~g}$ of soya peptone, $1 \mathrm{~g}$ of sodium acetate $\cdot 3 \mathrm{H}_{2} \mathrm{O}, 1 \mathrm{~g}$ of $\mathrm{K}_{2} \mathrm{HPO}_{4}, 0.27 \mathrm{~g}$ of $\mathrm{MgSO}_{4} \cdot 7 \mathrm{H}_{2} \mathrm{O}, 0.1$ $\mathrm{g}$ of sodium glutamate, $0.2 \mathrm{mg}$ of thiamine- $\mathrm{HCl}$, and $0.05 \mathrm{mg}$ of biotin. All strains were cultivated at $25^{\circ} \mathrm{C}$.

Extraction of DNA and determination of rRNA gene se- 
TABLE 1. Mean levels of sequence similarity of Caryophanon spp., Kurthia spp., Exiguobacterium spp., and "Bacillus aminovorans" to representative species of Bacillus rRNA groups

\begin{tabular}{|c|c|c|c|c|}
\hline \multirow[b]{2}{*}{ Species } & \multicolumn{4}{|c|}{$\%$ Similarity to: } \\
\hline & $\begin{array}{c}\text { Caryophanon } \\
\text { spp. }\end{array}$ & $\begin{array}{c}\text { "Bacillus } \\
\text { aminovorans", }\end{array}$ & $\begin{array}{l}\text { Kurthia } \\
\text { spp. }\end{array}$ & $\begin{array}{l}\text { Exiguobacterium } \\
\text { spp. }\end{array}$ \\
\hline Bacillus subtilis & 91.1 & 91.9 & 89.5 & 90.0 \\
\hline Bacillus megaterium & 91.9 & 94.6 & 90.4 & 90.6 \\
\hline Bacillus badius & 93.0 & 95.7 & 90.7 & 90.9 \\
\hline Bacillus pasteurii & 93.2 & 94.1 & 92.5 & 90.9 \\
\hline Bacillus sphaericus & 96.3 & 93.3 & 92.6 & 89.7 \\
\hline Planococcus citreus & 93.4 & 94.0 & 91.3 & 91.6 \\
\hline Bacillus alvei & 88.6 & 88.8 & 86.1 & 87.8 \\
\hline Bacillus brevis & 89.7 & 89.5 & 88.8 & 88.6 \\
\hline Bacillus stearothermophilus & 89.6 & 91.0 & 87.9 & 88.7 \\
\hline Alicyclobacillus cycloheptanicus & 83.1 & 84.4 & 81.1 & 82.5 \\
\hline
\end{tabular}

quence. DNA was extracted from cells in the mid-logarithmic growth phase and was purified by the method of Lawson et al. (26). 16S rDNA fragments were generated by PCR (30) amplification by using Taq polymerase as previously described (19). The amplified product was purified by using a GENE-CLEAN II kit (Bio 101, Inc., La Jolla, Calif.) and was directly sequenced by using a Sequenase kit (USB Corp., Cleveland, Ohio) (19).

Analysis of sequence data. A total of 86 sequences $(2,12$, $29,36)$ were aligned by using programs in the Wisconsin molecular biology package (11) and were analyzed by using the Fitch-Margoliash (FM) distance-matrix (DM) method (16) and the neighbor-joining (NJ) method of Saitou and Nei (31). Newly determined sequences and Bacillus group 2 sequences (2) were analyzed by using the FM and NJ methods, the bootstrapped (14) DM method with Kimura's (22) parameters, and parsimony (plain, bootstrapped, and branch and bound $[14,27])$ methods, using the FITCH, NEIGHBOR, SEQBOOT, DNADIST, CONSENSE, DNAPARS, DNABOOT, and DNAPENNY programs, respectively, of Felsenstein's PHYLIP program package (15). Where appropriate, global rearrangement and random input order options were used. Uncertainties in relationships were assessed by using a reduced data set along with the maximum likelihood method (ML) (13) and the invariance tests of Lake (25) and Cavender (4) contained in the DNAML and DNAINVAR programs of Felsenstein (15). A statistical analysis of the DNAINVAR data was performed by using the formulae of Lake (25) adapted for the Minitab statistical package (Minitab, Inc.).

Nucleotide sequence accession numbers. The sequences which we determined have been deposited in the EMBL data library under the following accession numbers: "Bacillus aminovorans" NCIMB 8292 ${ }^{\mathrm{T}}$, X62178; Brevibacterium acetylicum NCIMB 9889, X70313; C. latum NCIMB $9533^{\mathrm{T}}$, X70314; C. tenue NCDO 2324 ${ }^{\mathrm{T}}$, X70315; Exiguobacterium aurantiacum NCIMB $11798^{\mathrm{T}}$, X70316; $K$. gibsonii NCIMB $9758^{\mathrm{T}}, \mathrm{X} 70320$; and $K$. zopfii NCIMB $9878^{\mathrm{T}}, \mathrm{X} 70321$.

\section{RESULTS}

The almost complete 16S rRNA gene sequences of " $\mathrm{Ba}$ cillus aminovorans," Brevibacterium acetylicum, C. latum,
C. tenue, Exiguobacterium aurantiacum, $K$. gibsonii, and $K$. zopfii were determined by PCR direct sequencing (19). These new sequences were aligned and compared with a data set consisting of 79 sequences, including the sequences of 53 Bacillus species and 26 members of other low-G+C-content gram-positive genera. A matrix of similarity values was calculated and subjected to FM and NJ analyses. All of the new strains examined were related to the group 2 bacilli (sensu Ash et al. (2) (Fig. 1). Both Caryophanon species were recovered deep within the group 2 bacilli and branched from a common line of descent leading to Bacillus sphaericus and Bacillus fusiformis. Exiguobacterium aurantiacum and Brevibacterium acetylicum were recovered together at the periphery of the cluster consisting of group 2 species. The Kurthia species were recovered well within the confines of the group 2 Bacillus cluster. Other analyses (data not shown) loosely grouped the Kurthia species with Exiguobacterium aurantiacum and Brevibacterium acetylicum. Using the NJ method, we recovered Bacillus badius and "Bacillus aminovorans" as a clade adjacent to group 2, but the FM analysis placed "Bacillus aminovorans" adjacent to the planococci, with Bacillus badius removed to the edge of the Bacillus group 1 cluster. FM and $\mathrm{NJ}$ analyses performed with a reduced data set that included all of the strains closely related to the group 2 bacilli, Sporosarcina halophila, and representative strains belonging to the other main Bacillus groups described by Ash et al. (2) generally clustered species in the same order in which they appeared when the large data set was used. Augmented FM and NJ analyses (13, 21, 22) produced essentially the same trees, with minor differences in branch lengths (Fig. 2). The mean homology values for the new species compared with representative species belonging to the major phylogenetic groups of Ash et al. (2) are shown in Table 1. The results of bootstrapping the augmented distances from the Kimura (22) model, followed by consensus analysis, supported all of the major groups outlined above (Fig. 2). However, the clades ExiguobacteriumKurthia, Bacillus badius-"Bacillus aminovorans," and Bacillus insolitus-S. ureae clades were shown to be unstable and were supported in $<70 \%$ of the bootstrapped trees.

The results of the parsimony analysis are shown in Fig. 3. All of the major groups obtained with the DM analysis were

FIG. 2. Distance matrix trees for group 2 bacilli. (a) Nonaugmented FM analysis. (b) augmented (Kimura) NJ analysis showing the percentages of occurrence of branches in bootstrapped trees. A., Alicyclobacillus. For an explanation of the other abbreviations see the legend to Fig. 1. 
(a)

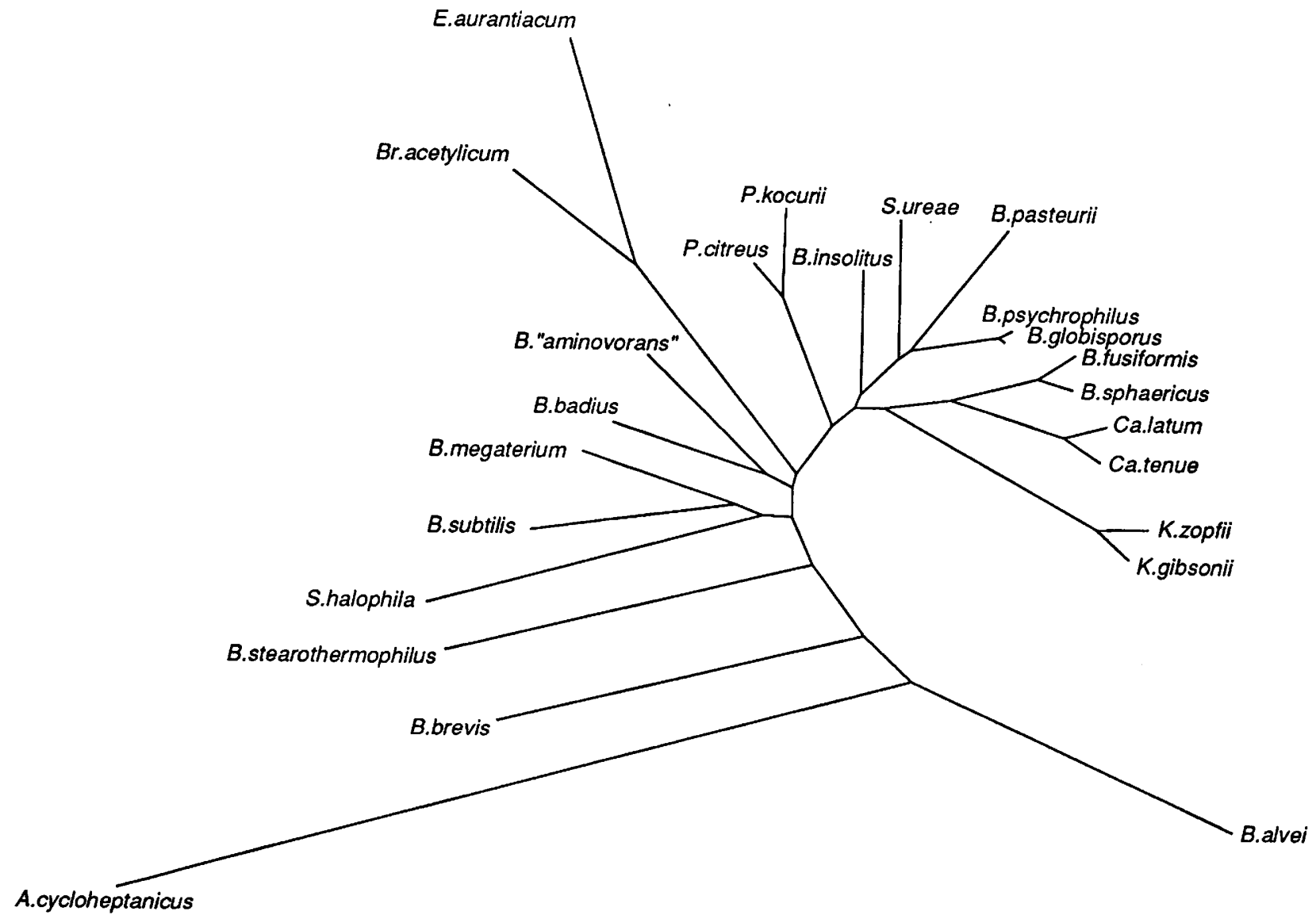

(b)

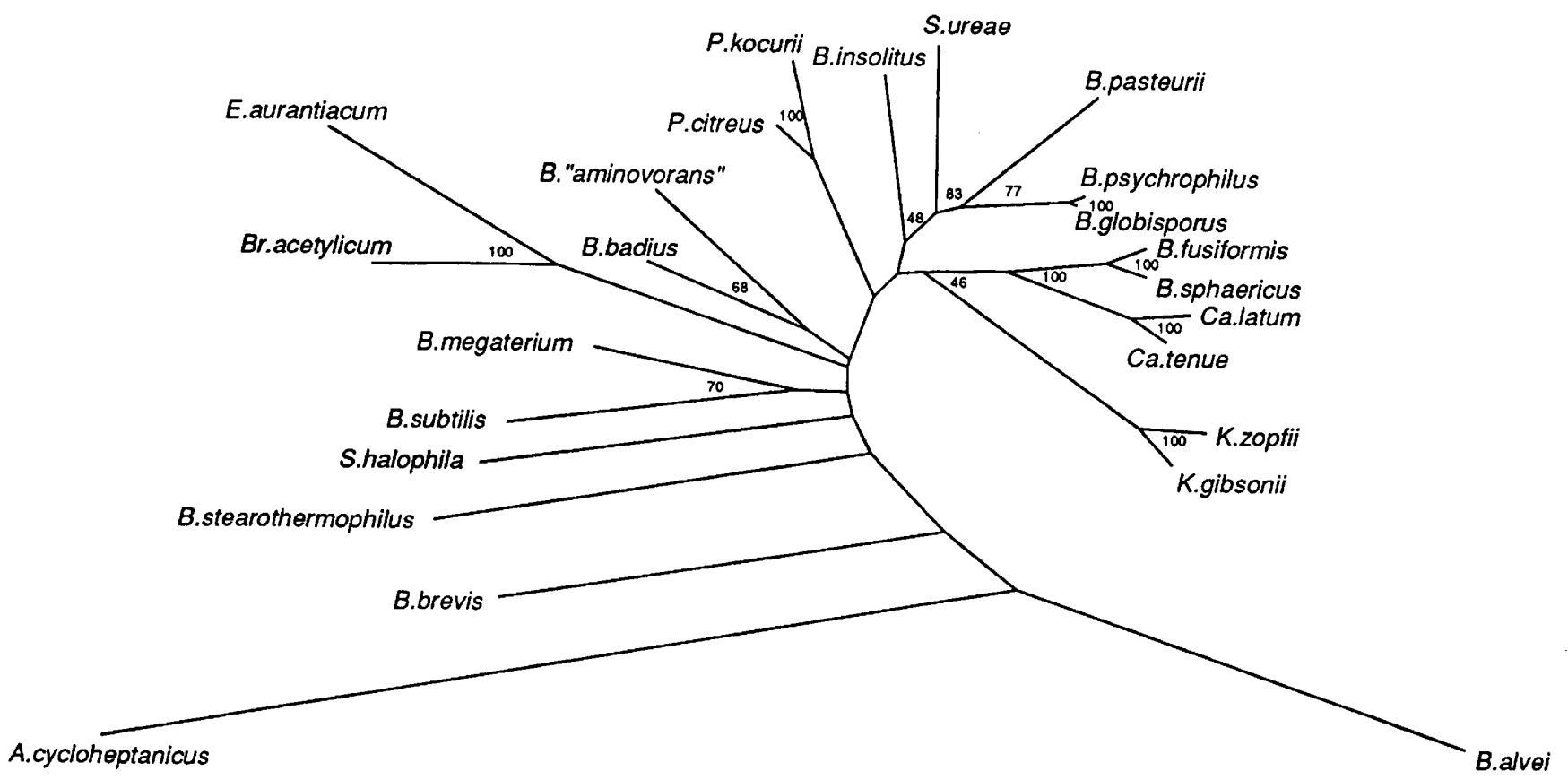




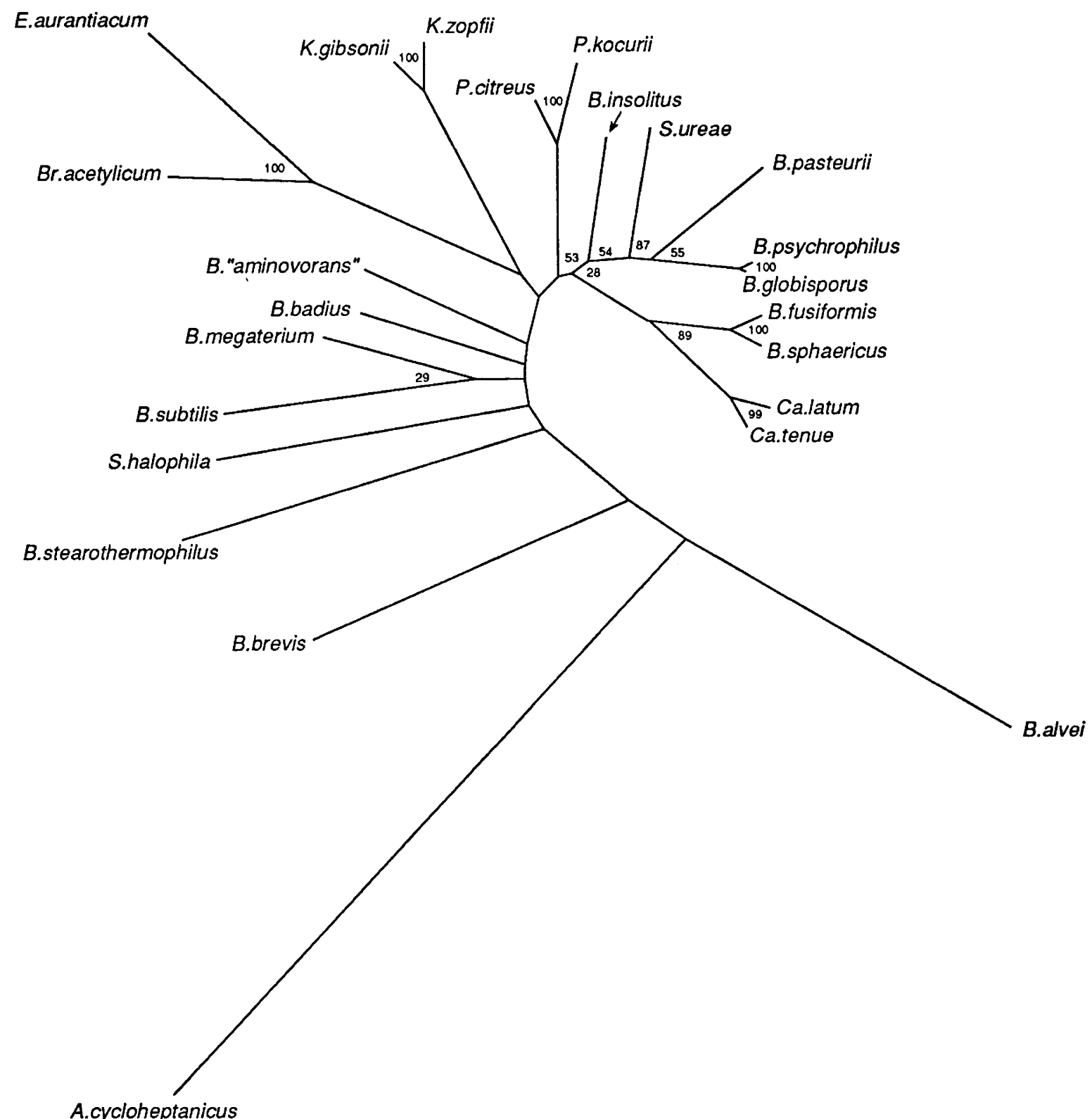

FIG. 3. Parsimony tree showing the variable branching positions of "Bacillus aminovorans" and Bacillus badius, along with the percentages of occurrence of branches in bootstrapped trees. Branch lengths were calculated by the DM method from the tree file. For an explanation of the abbreviations see the legends to Fig. 1 and 2.

supported by parsimony data, although some of the branching orders were altered. Bacillus badius and "Bacillus aminovorans" were recovered as separate lines of descent that were distant from the group 2 bacilli and appeared as a clade in only $39 \%$ of the bootstrapped trees. The Exiguobacterium clade was adjacent to the group 2 bacilli, together with the genus Kurthia, in agreement with the results obtained from branch and bound parsimony analysis (27), which also separated Bacillus badius and "Bacillus aminovorans" into adjacent lines of descent (data not shown). The results of a bootstrap analysis (14) of the parsimony data supported the following monophyletic groups at a confidence level of 95\%: Planococcus spp.; Kurthia spp.; Exiguobacterium aurantiacum and Brevibacterium acetylicum; Bacillus psychrophilus and Bacillus globisporus; Bacillus sphaericus and Bacillus fusiformis; and Caryophanon spp. The Bacillus sphaericus-Bacillus fusiformis clade and the Caryophanon group occurred in $89 \%$ of the bootstrapped parsimony trees. The group that included $S$. ureae, Bacillus pasteurii, Bacillus psychrophilus, and Bacillus globisporus was supported at a confidence level of $87 \%$. Bacillus insolitus was attached to this group ca. $50 \%$ of the time, indicating an unstable relationship. The association between Kurthia spp. and the Exiguobacterium aurantiacum-Brevibacterium acetylicum group was also supported in ca. $60 \%$ of the trees.

A maximum likelihood (13) analysis of the data set used for invariance tests also moved Bacillus insolitus to a branching point intermediate between the $S$. ureae group of strains and the Caryophanon-Bacillus sphaericus line. $B a$ cillus badius and "Bacillus aminovorans" were split by $P$. 
TABLE 2. Invariance analysis for group 2 bacilli and species that may be related to the group 2 bacilli

\begin{tabular}{|c|c|c|c|c|c|}
\hline \multirow[b]{2}{*}{ Species pair } & \multicolumn{5}{|c|}{ Results of: } \\
\hline & $\begin{array}{c}\text { Parsimony } \\
\text { analysis }\end{array}$ & $\begin{array}{l}\text { Background } \\
\text { analysis }\end{array}$ & $\begin{array}{l}\text { Chi-square } \\
\text { analysis }^{a}\end{array}$ & $\begin{array}{l}\text { Significance } \\
\text { analysis (\%) }\end{array}$ & $\begin{array}{c}\text { L-invariant } \\
\text { analysis }\end{array}$ \\
\hline Caryophanon latum-Caryophanon tenue & 14 & 2 & 9.01 & 99.7 & $-3,310$ \\
\hline Bacillus sphaericus-Bacillus fusiformis & 10 & 1 & 8.02 & 99.6 & $-6,792$ \\
\hline Planococcus citreus-Planococcus kocurii & 12 & 2 & 6.22 & 98.4 & $-7,957$ \\
\hline Exiguobacterium aurantiacum-Brevibacterium acetylicum & 14 & 5 & 4.38 & 96.1 & $-28,440$ \\
\hline Caryophanon tenue-Bacillus sphaericus & 10 & 3 & 3.21 & 92.2 & $-24,519$ \\
\hline Bacillus globisporus-Bacillus insolitus & 3 & 0 & 2.21 & 85.4 & $-25,435$ \\
\hline Bacillus globisporus-Bacillus pasteurii & 5 & 1 & 2.06 & 83.9 & $-16,759$ \\
\hline Bacillus globisporus-Sporosarcina ureae & 4 & 1 & 1.79 & 81.4 & $-21,070$ \\
\hline Bacillus insolitus-Bacillus pasteurii & 3 & 0 & 1.64 & 79.9 & $-23,919$ \\
\hline Bacillus insolitus-Sporosarcina ureae & 3 & 1 & 1.13 & 71.1 & $-26,674$ \\
\hline Bacillus pasteurii-Sporosarcina ureae & 4 & 1 & 1.53 & 78.1 & $-21,056$ \\
\hline Bacillus badius-"Bacillus aminovorans" & 4 & 2 & 1.34 & 74.6 & $-29,384$ \\
\hline Sporosarcina ureae-Sporosarcina halophila & 2 & 1 & 0.05 & 17.1 & $-41,876$ \\
\hline “Bacillus aminovorans"-Bacillus subtilis & 5 & 2 & 0.82 & 73.1 & $-44,204$ \\
\hline Bacillus badius-Bacillus subtilis & 4 & 2 & 0.91 & 75.4 & $-32,272$ \\
\hline Bacillus megaterium-Bacillus subtilis & 8 & 3 & 1.83 & 81.8 & $-28,792$ \\
\hline
\end{tabular}

${ }^{a}$ Chi-square analysis was performed with 1 degree of freedom.

citreus, with Bacillus badius closer to the group 1 bacilli (data not shown). The results of invariance tests $(4,25)$ supported the following relationships at a confidence level of 95\%: Exiguobacterium aurantiacum and Brevibacterium acetylicum; Planococcus spp.; Caryophanon spp.; and $\mathrm{Ba}$ cillus sphaericus and Bacillus fusiformis. The relationship between Caryophanon spp. and the Bacillus sphaericusBacillus fusiformis group was assessed at a level of significance of ca. $92 \%$. Cavender's $L$ invariants also supported the hypothesis that that there is a relationship between Bacillus psychrophilus and Bacillus globisporus. No other relationships were found to be statistically significant. Details of the results of the invariance analyses performed with group 2 strains are shown in Table 2.

\section{DISCUSSION}

$16 S$ rRNA cataloging $(6,17,33,34)$ and sequencing $(2,12$, $29,35)$ studies have done much to clarify the phylogentic divisions within the genus Bacillus and the relationships of these divisions to evolutionarily closely related genera. It is now clear that the concept of the genus Bacillus, as currently defined (5), is a phylogenetically meaningless concept and that taxonomic revision and redefinition are urgently needed $(2,33)$. The changes in the taxonomy of this group began with the removal of the extremely thermophilic, acidophilic bacilli to the new genus Alicyclobacillus (36). This was, however, a relatively easy step to take, given the enormous phylogenetic distances between these organisms and Bacillus subtilis (Fig. 1). The round-spore-forming bacilli and their asporogenous relatives (the group 2 bacilli) $(2,12)$ also form a separate taxon when phylogenetic analyses are performed $(2,12$; this paper). This group encompasses an evolutionary distance similar to that defined by the genus Alicyclobacillus (Fig. 1), and all of the members of the group 2 Bacillus cluster have been consistently shown to be phylogenetically distant from Bacillus subtilis (Table 1), the type species of the genus Bacillus. Indeed, in terms of evolutionary distance values, many asporogenous genera, such as the genera Brochothrix, Camobacterium, Enterococcus, and Staphylococcus, are as closely related to Bacil- lus subtilis as the group 2 bacilli and their relatives are. The concept of retaining the definition of the genus Bacillus and its species for the sake of ease of classification and identification while the related asporogenous genera are excluded is flawed by the current vague definition of the genus that it seeks to protect, by the impossibility of redefining the genus Bacillus in clear, meaningful terms, and by the phylogenetic evidence. Is it possible, for example, to consider Bacillus pasteurii a genuine member of the genus Bacillus, while $S$. ureae, its closest phylogenetic relative, is not a member of this genus or to consider Bacillus alvei, which is very remote phylogenetically, a member of the genus Bacillus, while Planococcus or Staphylococcus species are not (Fig. 1)? The simplest and most phylogenetically consistent policy would be to exclude the group 2 bacilli from the genus Bacillus. This would remove some of the phenotypic inconsistencies, such as murein types and spore shapes, from the definition of the genus Bacillus, together with some problematic species. Sufficient evidence has now accumulated to justify this removal. The phylogenetic status of the taxon that includes the group 2 bacilli needs to be resolved to clarify whether it represents a single genus or a group of closely related genera.

All of the phylogenetic analyses revealed considerable internal structure within the overall group comprising the group 2 bacilli. Several of the subdivisions were stable in all of the analyses, including the bootstrapping analysis. Exiguobacterium aurantiacum and Brevibacterium acetylicum always clustered together, sometimes as a separate clade (Fig. 1 [ML]) and sometimes loosely associated with the genus Kurthia (Fig. 3) but always at the boundaries of or outside the cluster that included the group 2 bacilli. Our data support the validity of the genus Exiguobacterium as the separate genus proposed by Collins et al. (10) within the overall radiation of genera associated with Bacillus sensu lato (Fig. 1) and are consistent with the suggested close affinity between Brevibacterium acetylicum and Exiguobacterium aurantiacum $(9,20)$. The phylogenetic distance between Brevibacterium acetylicum and Exiguobacterium aurantiacum is comparable to that between Enterococcus faecalis and Enterococcus cecorum (level of similarity, 
94.5\%) or between Lactococcus lactis and Lactococcus garvieae (7), which supports the single genus theory. The invariance analysis indicated that there is a significant relationship between Exiguobacterium aurantiacum and Brevibacterium acetylicum, but that this relationship is not as close as the relationships between the members of established genera, such as the genera Caryophanon and Planococcus. On the basis of the results of the phylogenetic analysis and the high levels of chemotaxonomic similarity (9) of these organisms, we propose that Brevibacterium acetylicum should be reclassified in the genus Exiguobacterium as Exiguobacterium acetylicum comb. nov. The two Kurthia species clustered at the periphery of the group 2 bacilli in all of our analyses, frequently adjacent to the CaryophanonBacillus sphaericus branch. An apparent relationship to the genus Exiguobacterium, another peripheral group, was not supported by the bootstrap analysis results. The results of the invariance analysis (Table 2$)(4,25)$ did not support the hypothesis that there is a relationship between the genus Exiguobacterium and the genus Kurthia or the hypothesis that these genera are related to Bacillus subtilis or representatives of the group 2 bacilli. Thus, the genus Kurthia represents a distinct, somewhat distant line of descent within the overall phylogenetic structure of the group 2 bacilli (Fig. 1).

Stackebrandt et al. (33) found close relationships between $P$. citreus and "Bacillus aminovorans" (similarity coefficient, 0.75) and between Bacillus insolitus and "Bacillus aminovorans" (similarity coefficient, 0.73 ) by using $16 \mathrm{~S}$ rRNA oligonucleotide cataloging. We were unable to confirm the second relationship in any of our analyses. However, we were able to confirm the first relationship in the absence of Bacillus badius (a peripheral member of the group 1 bacilli) (2) by using FM analysis (data not shown) and more complete sequence data. All of the analyses placed "Bacillus aminovorans" and the planococci on separate lines of descent (Fig. 3). The association between Bacillus badius and "Bacillus aminovorans" was supported approximately $60 \%$ of the time by the results of the bootstrapped NJ analysis, was not supported by the results of the FM analysis, and was supported $40 \%$ of the time by the results of the bootstrapped parsimony analysis, indicating that the relationship is unstable. Although these species apparently exhibit high levels of sequence homology to the group 2 bacilli (Table 1), treeing analyses always recovered them at the boundaries of, or outside, this latter group. The results of invariance tests did not support relationships of these species to the representative group 2 Bacillus species, to Bacillus subtilis, or to each other. The presence of meso-diaminopimelic acid in the cell wall mureins of Bacillus badius and "Bacillus aminovorans" (33), rather than the L-lysine or D-ornithine of the true group 2 bacilli, suggests these species are not members of this group. Bacillus badius and "Bacillus aminovorans" are clearly not related closely enough to Bacillus subtilis (Tables 1 and 2) to be considered true bacilli (2; this paper), nor are they related closely enough to each other to form a single, stable line of descent in phylogenetic analyses. Further studies will be necessary to determine whether these species are indeed truly phylogenetically peripheral to the genus Bacillus and warrant separate genera.

Within group 2 proper, four groups centered on the genus Planococcus, $S$. ureae, the genus Caryophanon, and Bacillus sphaericus were recovered in all analyses. These groups were considered to be members of a single cluster in the cataloging study of Stackebrandt et al. (33). With the excep- tion of Bacillus insolitus attached to the $S$. ureae group, the clusters are supported by the results of the bootstrap analysis at a minimum level of $83 \%$. While these four groups could be considered members of a single genus, there are several arguments against this concept. First, the mean homology data shown in Table 1 indicate that these four groups are not particularly closely related to each other. Fox et al. (18) and Kita-Tsukamoto et al. (23) have suggested boundary criteria for families and genera based on sequence homology data. Our four groups could be considered beyond the boundary for species belonging to the same genus according to these criteria, with the exception of the Caryophanon-Bacillus sphaericus-Bacillus fusiformis line of descent (Table 1). Second, although the branching positions of the four groups may change with respect to the main evolutionary line, according to the analysis used, internally they are stable and supported by the results of bootstrapping analysis. The branching order of the $S$. ureae group is itself stable to analysis (Fig. 1 through 3 [ML]). Third, the results of invariance analysis do not support very close relationships between the groups (Table 2). A single genus based on these four groups would not, in our opinion, represent much taxonomic progress. There would still be the problem of reconciling gross morphological, physiological, and biochemical differences with the known phylogeny, albeit on a smaller, more manageable scale. We believe that each of the four groups is sufficiently distinct to warrant a separate genus.

S. ureae, Bacillus pasteurii, Bacillus psychrophilus, and Bacillus globisporus clustered together in all of the analyses and formed a stable line of descent, supported by bootstrapping data, on the main tree. The branching order within this line of descent was identical in all analyses. This stability could be used as evidence for assigning these species to a single redefined genus, the genus Sporosarcina. Bacillus insolitus was usually associated with this group, but often it was in an adjacent, rather than internal, position (Fig. 2 and 3 [ML]). However, the results of invariance analyses indicate that $S$. ureae, Bacillus pasteurii, Bacillus psychrophilus, and Bacillus insolitus are not particularly closely related. This is perhaps surprising, given the stability of the line of descent as determined by DM and other analyses and the relatively short genetic distances between the species. The valid species $S$. halophila (Claus et al.) is phylogenetically distant from $S$. ureae (12) (Fig. 1 through 3 and Table 2). S. halophila is not sufficiently close to Bacillus subtilis to warrant transfer to the genus Bacillus sensu stricto (Table 2), nor is it related to any other known genus in the overall radiation of gram-positive bacteria examined to date (12) (Fig. 1). Krych et al. (24) showed that Bacillus sphaericus contains six DNA-DNA homology groups and that Bacillus sphaericus, as exemplified by the type strain, exhibited the lowest levels of homology to the other five groups. DNA homology group $2 \mathrm{~b}$ (24) corresponded to Bacillus sphaericus subsp. fusiformis, and this taxon was elevated to species status by Priest et al. (28). No proposals for separate specific status have been made so far for the other homology groups, although a strain described as "Bacillus rotans" was recovered in DNA homology group III (24) and strains pathogenic for mosquito larvae also appear to form a distinct group (1). Judging from the data of Krych et al. (24), it is probable that all six of the homology groups are members of the genus centered on Bacillus sphaericus. The genus Caryophanon (Peshkoff) and the Bacillus sphaericus group share a common departure point from the main tree, and this relationship was apparent in all of our analyses except the invariance 
analysis. However, these taxa are sufficiently distinct from each other to warrant separate generic status for the two groups. The revival of the species $C$. tenue (Trentini) was justified. In this study, $C$. tenue was found to be closely related to, but distinct from, $C$. latum. Both Planococcus species were significantly related as determined by all analyses and were distinct from the other groups. "Bacillus aminovorans" was not found to be related to the planococci. The separate status of the genus Planococcus should therefore be retained.

Bacillus rRNA group 2 has been shown to be stable to phylogenetic analysis $(2,12$; this paper) and to consist of a cluster of related genera. Therefore, it seems likely that this group should be given the phylogenetic status of a family.

Taxonomic proposal. We propose that Brevibacterium acetylicum should be transferred to the genus Exiguobacterium as Exiguobacterium acetylicum (Levine and Soppeland) comb. nov. A full description of Exiguobacterium acetylicum is given in reference 20. The type strain of Exiguobacterium acetylicum is ATCC 953.

\section{ACKNOWLEDGMENTS}

We are grateful to MAFF for supporting this work.

Robert Anderson of the Institute of Food Research devised the computer program used for automating the invariance analysis.

\section{REFERENCES}

1. Alexander, B., and F. G. Priest. 1990. Numerical classification and identification of Bacillus sphaericus, including some strains pathogenic for mosquito larvae. J. Gen. Microbiol. 136:367376.

2. Ash, C., J. A. E. Farrow, S. Wallbanks, and M. D. Collins. 1991. Phylogenetic heterogeneity of the genus Bacillus revealed by comparative analysis of small-subunit ribosomal RNA sequences. Lett. Appl. Microbiol. 13:202-206.

3. Belikova, V. L., N. V. Cherevach, L. M. Baryshnikova, and L. V. Kalikoutskii. 1980. Morphologic, physiologic and biochemical characteristics of Kurthia zopfii. Microbiology (Engl. Transl. Mikrobiologiya) 49:51-55.

4. Cavender, J. A. 1989. Mechanised derivations of linear invariants. Mol. Biol. Evol. 6:301-316.

5. Claus, D., and R. C. W. Berkeley. 1986. Genus Bacillus Cohn 1872, p. 1105-1140. In P. H. A. Sneath, N. S. Mair, M. E. Sharpe, and J. G. Holt (ed.), Bergey's manual of systematic bacteriology, vol. 2. The Williams and Wilkins Co., Baltimore.

6. Clausen, V., J. G. Jones, and E. Stackebrandt. 1985. 16S ribosomal RNA analysis of Filibacter limicola indicates a close relationship to the genus Bacillus. J. Gen. Microbiol. 131:26592663.

7. Collins, M. D., C. Ash, J. A. E. Farrow, S. Wallbanks, and A. M. Williams. 1989. 16S ribosomal ribonucleic acid sequence analysis of lactococci and related taxa. Description of Vagococcus fluvialis gen. nov., sp. nov. J. Appl. Bacteriol. 67:453-460.

8. Collins, M. D., M. Goodfellow, and D. E. Minnikin. 1979. Isoprenoid quinones in the classification of coryneform and related bacteria. J. Gen. Microbiol. 110:127-136.

9. Collins, M. D., and R. Kroppenstedt. 1983. Lipid composition as a guide to the classification of some coryneform bacteria containing an $\mathrm{A} 4 \alpha$ type peptidoglycan (Schleifer and Kandler). Syst. Appl. Microbiol. 4:95-104.

10. Collins, M. D., B. M. Lund, J. A. E. Farrow, and K.-H. Schleifer. 1983. Chemotaxonomic study of an alkalophilic bacterium, Exiguobacterium aurantiacum, gen. nov., sp. nov. J. Gen. Microbiol. 129:2037-2042.

11. Devereux, J., P. Haeberli, and D. Smithies. 1984. A comprehensive set of sequence programs for the VAX. Nucleic Acids Res. 12:387-395.
12. Farrow, J. A. E., C. Ash, S. Wallbanks, and M. D. Collins. 1992. Phylogenetic analysis of the genera Planococcus, Marinococcus and Sporosarcina and their relationships to members of the genus Bacillus. FEMS Microbiol. Lett. 93:167-172.

13. Felsenstein, J. 1981. Evolutionary trees from DNA sequences: a maximum likelihood approach. J. Mol. Evol. 17:338-376.

14. Felsenstein, J. 1985. Confidence limits on phylogenies: an approach using the bootstrap. Evolution 39:783-791.

15. Felsenstein, J. 1989. PHYLIP-phylogeny inference package (version 3.2) Cladistics 5:164-166.

16. Fitch, W. M., and E. Margoliash. 1967. Construction of phylogenetic trees: a method based on mutation distances as estimated from cytochrome c sequences is of general applicability. Science 155:279-284.

17. Fox, G. E., K. J. Pechman, and C. R. Woese. 1977. Comparative cataloguing of $16 \mathrm{~S}$ ribosomal ribonucleic acid: molecular approach to prokaryotic systematics. Int. J. Syst. Bacteriol. 27:44-57.

18. Fox, K. F., A. Brown, A. Fox, and G. Schnitzer. 1991. Tatlockia, a genetically and chemically distinct group of bacteria. Proposal to transfer Legionella maceachernii (Brenner et al.) to the genus Tatlockia, as Tatlockia maceachernii comb. nov. Syst. Appl. Microbiol. 14:52-56.

19. Hutson, R. A., D. E. Thompson, and M. D. Collins. 1993. Genetic interrelationships of saccharolytic Clostridium botulinum types $\mathrm{B}, \mathrm{E}$ and $\mathrm{F}$ and related clostridia as revealed by small-subunit rRNA gene sequences. FEMS Microbiol. Lett. 108:103-110.

20. Jones, D., and R. M. Keddie. 1986. Genus Brevibacterium Breed 1953, p. 1301-1313. In P. H. A. Sneath, N. S. Mair, M. E. Sharpe, and J. G. Holt (ed.), Bergey's manual of systematic bacteriology, vol. 2. The Williams and Wilkins Co., Baltimore.

21. Jukes, T. H., and C. P. Cantor. 1969. Evolution of protein molecules, p. 21-132. In H. N. Munro (ed.), Mammalian protein metabolism, vol. 3. Academic Press, New York.

22. Kimura, M. 1980. A simple method for estimating evolutionary rates of base substitutions through comparative studies of nucleotide sequences. J. Mol. Evol. 16:111-120.

23. Kita-Tsukamoto, K., H. Oyaizu, K. Nanba, and U. Simudu. 1993. Phylogenetic relationships of marine bacteria, mainly members of the Vibrionaceae, determined on the basis of $16 \mathrm{~S}$ rRNA sequences. Int. J. Syst. Bacteriol. 43:8-19.

24. Krych, K. K., J. L. Johnson, and A. A. Yousten. 1980. Deoxyribonucleic acid homologies among strains of Bacillus sphaericus. Int. J. Syst. Bacteriol. 30:476-484.

25. Lake, J. A. 1987. A rate-independent technique for analysis of nucleotide sequences: evolutionary parsimony. Mol. Biol. Evol. 4:167-191.

26. Lawson, P. A., S. E. Gharbia, H. N. Shah, and D. R. Clark. 1989. Recognition of Fusobacterium nucleatum subgroups Fn-1, Fn-2 and Fn-3 by ribosomal RNA gene restriction patterns. FEMS Microbiol. Lett. 65:41-46.

27. Penny, D., and M. D. Hendy. 1985. Testing methods of evolutionary tree construction. Cladistics 1:266-272.

28. Priest, F. G., M. Goodfellow, and C. Todd. 1988. A numerical classification of the genus Bacillus. J. Gen. Microbiol. 134:18471882.

29. Rossler, D., W. Ludwig, K.-H. Schleifer, C. Lin, T. J. McGill, J. D. Wisotzkey, P. Jurtshuck, Jr., and G. E. Fox. 1991. Phylogenetic diversity in the genus Bacillus as seen by $16 \mathrm{~S}$ rRNA sequencing studies. Syst. Appl. Microbiol. 14:266-269.

30. Saiki, R. K., D. H. Gelford, S. Stafford, S. J. Scharf, R. Higuchi, G. T. Horn, K. G. Mullis, and E. H. Erlich. 1988. Primer directed enzymatic amplification of DNA with a thermostable DNA polymerase. Science 239:487-491.

31. Saitou, N., and M. Nei. 1987. The neighbor-joining method: a new method for reconstructing phylogenetic trees. Mol. Biol. Evol. 4:406-425.

32. Shaw, S., and R. M. Keddie. 1984. The genus Kurthia: cell wall composition and DNA base content. Syst. Appl. Microbiol. 5:220-224.

33. Stackebrandt, E., W. Ludwig, M. Weizenegger, S. Dorn, T. J. 
McGill, G. E. Fox, W. Schubert, and K.-H. Schleifer. 1987. Comparative 16S rRNA oligonucleotide analysis and murein types of round-spore-forming bacilli and non-spore-forming relatives. J. Gen. Microbiol. 133:2523-2529.

34. Stackebrandt, E., and C. R. Woese. 1977. A phylogenetic dissection of the family Micrococcaceae. Curr. Microbiol. 2:317-322.

35. Wisotzkey, J. D., P. Jurtshuk, Jr., and G. E. Fox. 1990. PCR amplification of $16 \mathrm{~S}$ rDNA from lyophilized cell culture facili- tates studies in molecular systematics. Curr. Microbiol. 21:325327.

36. Wisotzkey, J. D., P. Jurtshuk, Jr., G. E. Fox, G. Deinhard, and K. Poralla. 1992. Comparative sequence analysis on the $16 \mathrm{~S}$ rRNA of Bacillus acidocaldarius, Bacillus acidoterrestris and Bacillus cycloheptanicus: proposal for a new genus Alicyclobacillus gen. nov. Int. J. Syst. Bacteriol. 42:263-269.

37. Woese, C. R. 1987. Bacterial evolution. Microbiol. Rev. 51:221271. 